\title{
LOW-LOAD RESISTANCE EXERCISE IMPROVES COGNITIVE FUNCTION IN OLDER ADULTS
}

\author{
EXERCICIO RESISTIDO COM BAIXA CARGA MELHORA A FUNÇÃO COGNITIVA EM IDOSOS
}

EJERCICIO RESISTIDO COM BAJA CARGA MEJORA LA FUNCIÓN COGNITIVA EN ADULTOS MAYORES

Original Article

Artigo OriginaL

Artículo Original

\begin{abstract}
Amanda Veiga Sardeli1,2
(Physical Education Professional)

Marina Lívia Venturini Ferreira ${ }^{2}$

(Physical Education Professional)

Lucas do Carmo Santos ${ }^{2}$

(Physical Education Professional)

Marília de Souza Rodrigues ${ }^{2}$

(Physical Education Professional)

Alfredo Damasceno ${ }^{3}$

(Physician)

Cláudia Regina Cavaglieri ${ }^{1,2}$

(Pharmacist)

Mara Patrícia Traina Chacon-Mikahil1,2 (Physical Education Professional)
\end{abstract}

\section{Universidade Estadual de Campinas (UNICAMP), Faculdade de Ciências Médicas, Programa de Gerontologia, Campinas, SP, Brazil. 2. Faculdade de Educação Física (UNICAMP), Laboratório de Fisiologia do Exercício (FISEX), Campinas, SP, Brazil. \\ 3. Faculdade de Ciências Médicas, UNICAMP, Department of Neurology, Campinas, SP, Brazil.}

\section{Correspondence:}

Amanda Veiga Sardeli

Faculdade de Educação Física (UNICAMP), Laboratório de

Fisiologia do Exercício (FISEX). Av. Érico Veríssimo, 701, Campinas, SP, Brazil.13083-851.

amandaveigasardeli@yahoo.com.br

\begin{abstract}
Introduction: Resistance exercise (RE) training is widely recommended for increasing muscle strength and mass in older adults. RE is also a potential stimulus to improve cognitive functions (CF), but the best protocol for this purpose is unknown. Objective: To compare the effects of different RE protocols on CF in the same group of individuals. Methods: Twenty-four older adults were randomized (cross over) to control (CON) and lower limb RE protocols with high load (HL - 80\% of 1RM), low load (LL - 30\% of 1RM) and LL with blood flow restriction (LL-BFR - 30\% of 1RM and 50\% BFR). For CF assessment, participants underwent the Stroop test before and after each RE protocol. Results: Reduction in response time for Stroop neutral stimuli was greater after LL (effect size $(E S)=-0.92)$ compared to CON (ES $=-0.18)$ and HL ( $E S=-0.03)$, but was not different from LL-BFR $(E S=-0.24)$. The reduced response time was associated with reduced parasympathetic modulation and increased cardiac output across protocols. Conclusion: LL was the most effective RE protocol to improve CF of older adults and a potential beneficial effect of LL-BFR on CF (non-significant) was identified. Therefore, LL resistance exercise appears to stimulate acute cognitive improvements in healthy older adults, probably through exercise-induced optimal autonomic modulation changes. Level of Evidence l; Therapeutic studies-Investigating the results of treatment.
\end{abstract}

Keywords: Elderly; Cognition; Exercise therapy; Health promotion.

\section{RESUMO}

Introdução: O treinamento com exercício resistido (ER) é amplamente recomendado para aumento de força e massa muscular em idosos. O ER também é um possivvel estímulo para melhorar funções cognitivas (FC), mas o melhor protocolo para essefim não éconhecido. Objetivo: Comparar os efeitos de diferentes protocolos de ER sobre a FC de um mesmo grupo de individuos. Métodos: Vinte equarto idosos foram randomizados (cross-over) em grupo controle (CON) egrupos protocolos de ER para membros inferiores com carga alta (CA - 80\% 1RM), carga baixa (CB - 30\% 1RM) e carga baixa com restrição de fluxo sanguíneo (CB-RFS - 30\% 1RM e 50\% RFS). Para a avaliação de FC, os participantes realizaram o teste de Stroop antes e depois de cada protocolo de ER. Resultados: A redução do tempo de resposta para o estímulo neutro de Stroop foi maior após O CB (tamanho de efeito [TE] =-0,92) comparado ao CON $(T E=-0,18)$ e CA (TE =-0,03), mas não foi diferente de CB-RFS (TE =-0,24). A redução do tempo de resposta foi associada à redução da modulação parassimpática e ao aumento de débito cardíaco em todos os protocolos. Conclusões: CB foi o protocolo de ER mais eficiente para aumentar a FC em idosos e identificou-se um efeito benéfico em potencial do CB-RFS sobre a FC (não significante). Desta forma, o exercício resistido de CB parece estimular a melhora aguda da função cognitiva em idosos saudáveis, provavelmente devido à alteração ideal da modulação autonômica induzida pelo exercício. Nível de Evidência l; Estudos Terapêuticos - Investigação dos resultados do tratamento.

Descritores: Idosos; Cognição; Terapia por exercício; Promoção da saúde.

\section{RESUMEN}

Introducción: El entrenamiento con ejercicio resistido (ER) es ampliamente recomendado para aumento de fuerza y masa muscular en ancianos. El ER también es un posible estímulo para mejorar las funciones cognitivas (FC), pero el mejor protocolo para este fin no es conocido. Objetivo: Comparar los efectos de diferentes protocolos de ER sobre la FC de un mismo grupo de individuos. Métodos: Veinte y cuatro ancianos fueron aleatorizados (cross-over) en grupo control (CON) y grupos protocolos de ER para extremidades inferiores con carga alta (CA - 80\% 1RM), carga baja (CB - 30\% 1RM) y carga baja con restricción de flujo sanguineo (CB-RFS-30\% 1RMy50\% RFS). Para la evaluación de FC, los participantes realizaron el test de Stroop antesy después de cada protocolo de ER. Resultados: La reducción del tiempo de respuesta para el estímulo neutro de Stroop fue mayor después del $C B$ (tamaño de efecto $[T E]=-0,92)$ comparado al CON (TE $=-0,18)$ y CA (TE $=-0,03)$, pero no fue diferente de CB-RFS (TE $=-0,24)$. La reducción del tiempo de respuesta fue asociada a la reducción de la modulación parasimpática y al aumento del gasto cardiaco en todos los protocolos. Conclusiones: CB fue el protocolo de ER más eficiente para aumentar la FC en ancianos y se identificó un efecto beneficioso potencial del CB-RFS sobre la FC (no significativo). De esta forma, el ejercicio resistido de CB parece estimular la mejora aguda de la función cognitiva en ancianos sanos, probablemente debido a la alteración ideal de la modulación autonómica inducida por el ejercicio. Nivel de Evidencia l; Estudios Terapéuticos - Investigación de los resultados del tratamiento.

Descriptores: Ancianos; Cognición; Terapia por ejercicio; Promoción de la salud. 


\section{INTRODUCTION}

Along with natural aging process there are numerous structural and functional changes that lead to a progressive loss of muscle strength and mass. ${ }^{1}$ Resistance training has been widely recommended for improvement of such age-related muscle impairments. ${ }^{2}$

Aging process also culminates in reduction of performance and some cognitive abilities, such as memory, executive processing and information processing speed. ${ }^{3}$ To mitigate these processes both endurance or resistance training have been prescribed, and both have shown ability to increase neuronal density, synapses, neurotransmitters, yielding improvements in cognitive function (CF) ${ }^{4,5}$

Incipient evidence showed that CF benefits are not limited to chronic training effects and improvements can also be observed immediately after a single exercise session., ${ }^{6,7}$ For example, Pontiflex et al. ${ }^{6}$ observed working memory and reaction time improvements after an endurance session in young individuals, but not after RE, while Alves et al. ${ }^{7}$ found similar CF improvements after both endurance and RE sessions in older adults. Although there is a wide body of evidence proving the chronic effects of exercise on CF, studies investigating the acute effects are scarce.

In addition, cognitive effects of blood flow restriction (BFR) RE have not yet been explored in the literature, even though it is an excellent choice in the elderly population since its neuromuscular benefits are reached with very low osteoarticular overload. ${ }^{8}$ Considering endurance exercise has increased CF at an intensity-dependent manner partially mediated by sympathetic modulation activity and/or brain blood flow increases during the recovery period, ${ }^{9-11}$ we expect the extra sympathetic outflow stimulation from muscle metaboreflex after BFR RE could leads to additional CF benefits.

In this setting, the present study aimed to compare the effects of three different RE protocols (high load and low load with and without blood flow restriction) in cognitive performance of healthy older adults. Although all proposed protocols are known to be effective to muscle mass and strength gains in elderly population, 8,12,13 their effects on CF have not been compared.

\section{METHODS}

We enrolled 24 healthy untrained older adults. The study was performed at the Faculty of Physical Education, University of Campinas, Brazil. A clinical examination was carried out, and subjects were excluded if they have less than 60 years old, coronary artery disease, hypertension, insulin-dependence, chronic obstructive pulmonary disease, limiting osteoarticular diseases, cigar addiction, $\mathrm{BMI}>30 \mathrm{~kg} / \mathrm{m}^{2}$, and/or if they use any medication that could interfere in the physiological responses of evaluations. The study was approved by the ethics committee of University of Campinas (1.198.571) and an informed consent was obtained from all participants.

Subjects performed a familiarization trial in a $45^{\circ}$ leg press equipment (Nakagym, São Paulo, Brazil) with BFR followed by a maximal strength test. Participants performed the experimental sessions in a cross-over design (Latin square design), between 7am and 12pm, controlled environmental temperature, with one week interval between them. Preceding sessions, subjects were instructed to avoid drinking alcohol, coffee or other caffeinated beverages for the $12 \mathrm{~h}$, remain fasted for $2 \mathrm{~h}$, sleep well and to refrain from exercise for at least $72 \mathrm{~h}$ before assessments. During protocols, the subject's health statuses were verified and the experimental sessions were reallocated whenever necessary.

Experimental sessions were performed in the same leg press equipment, with a standardized warm-up consisting in 10 repetitions with $30 \%$ of maximal strength and standardized rest interval of one minute between sets. The protocols applied were the following: (1) Control session (CON), which consisted of 10 minutes resting seated in the $45^{\circ}$ leg press equipment; (2) High load RE (HL), four sets performed until voluntary failure with $80 \%$ of one-repetition maximum (1RM); (3) Low load RE (LL), four sets performed until voluntary failure with $30 \%$ of 1RM; (4) and LL-BFR, one set of 30 repetitions followed by three sets of 15 repetitions with $30 \%$ of $1 \mathrm{RM}$ and with blood flow restriction - $50 \%$ of the individual leg systolic blood pressure along all exercise session. For LL-BFR session the blood-pressure cuff (175 $\mathrm{mm}$ width and $920 \mathrm{~mm}$ length) was attached in the quadriceps inguinal fold region and the restriction was maintained also during time intervals. To ensure that participants reached the voluntary failure we checked the ratio of perceived exertion (RPE), with a 6-20 points Borg scale.

Assessed by a 1RM test in leg press equipment, according to descriptions of Brown et al. ${ }^{14}$ The subjects performed 10 repetitions at $50 \%$ of their estimated 1RM. After 3 min of rest, the subjects performed three repetitions at $70 \%$ of their estimated 1RM, and after other 3 min rest, trials were performed for 1RM with progressively heavier weights until the 1 RM was determined within five attempts, with 3-5 min of rest among trials. All subjects were tested and retested in two separated sessions with 72 -h rest among them. We registered the highest load obtained after the test-retest.

We applied the computerized Stroop test TESTINPACS ${ }^{\circledR} .15$ The laptop was placed over the participant legs and they used the forefingers of both hands to press one of the two options of the keyboard key $([\leftarrow]$ or $[\rightarrow])$. First, the participants had to choose the right name for the color displayed on the screen and it was used to warm up the participants as well as to evaluate their color perception. After that, participants had to choose the right name for the color writing with the letters colored always in white (neutral stimuli). Finally, participants had to choose the right name of the color of the word letters instead the name of the color written (incongruent stimuli). After receiving the instructions, they performed one familiarization trial. The test was performed pre and post exercise (or control session). The software registered the number of hits (correct answers) and answer time to each stimulus. Mean answer time and overall number of hits were registered for each step (12 random stimuli).

Continuous R-R intervals were acquired pre and post exercise, seated in the $45^{\circ}$ leg press equipment, using a heart rate monitor (Polar RS800CX, Kempele, Finland). ${ }^{16}$ Data were uploaded at Polar ProTrainer 5 software and heart rate variability (HRV) was analyzed during five minutes of stationary R-R intervals in Kubios HRV analysis software (MATLAB, version 2 beta, Kuopio, Finland). The HRV indexes analysed at time domain were: mean R-R interval (RRi), standard deviation of all normal RR intervals (SDNN) and square root of the mean squared differences of successive R-R intervals (RMSSD), which represents parasympathetic modulation. The frequency domain indices were derived by a Fast Fourier Transform and included absolute units high frequency $\left(\mathrm{HFms}^{2}\right)$, normalized units low frequency (LFnu) and LF/HF ratio, which represents parasympathetic, sympathetic and sympathovagal balance, respectively. ${ }^{17}$

Heart rate (HR), cardiac output (CO) and total peripheral resistance (TPR) were continuously recorded and derived from noninvasive beat-to-beat arterial blood pressure waveforms, ${ }^{18}$ obtained by the photoplethysmography using Finometer Pro ${ }^{\circledR}$ (FMS-Finapres Medical System, Arnhen, Netherlands). The participants were instructed to rest awake and quiet during the photopletismography applied on the middle finger. ${ }^{19}$

We measured the individual BFR pressure prior to all sessions. Following 5 minutes of rest in supine position, a vascular Doppler probe (DV-600; Marted, Ribeirão Preto, São Paulo, Brazil) was placed over the tibial artery to capture its auscultatory pulse while a standard blood pressure cuff was positioned in the quadriceps inguinal fold region. Cuff was inflated up to the point at which the auscultatory pulse was interrupted..$^{20}$ 


\section{Statistical analyses}

The Shapiro-Wilk normality test showed that CF measurements were not normally distributed. Thus, we applied the non-parametric Friedman test $(p<0.05)$, followed by Wilcoxon post-hoc test with a Bonferroni correction ( $p<0.008$ ), to compare CF at pre moments and the delta of change (post minus pre) among the 4 experimental protocols. To test educational level effects on CF, we also performed a Qui square test comparing the answer time and number of hits for each Stroop step among the three educational levels. To complement the description of our findings, we also presented the effect size ( $E S=$ Cohen's d) of CF within each experimental protocol. Data is present in median and interquartile range. Analyses were conducted using SPSS-18.0 software (SPSS INC., Chicago, IL, USA).

\section{RESULTS}

Along data collection, three participants dropped out of the study. Baseline characteristics of the participants and the experimental sessions are described in Table 1 and 2, respectively. Although correlation analyses showed that individuals with higher educational level had lower answer time in each Stroop step (neutral stimuli pre: $r=-0.36, p=0.001$; neutral stimuli post: $r=-0.34, p=0.001$; incongruent stimuli pre: $r=-0.22, p=0.04$; incongruent stimuli post: $r=-0.22, p=0.03$ ), there was no association between delta of changes in answer time after exercise and educational level ( $p>0.2)$.

There were no differences in pre exercise answer time and number of hits among protocols. The comparison between changes (post minus pre) for number of hits showed no difference among protocols. (Table 3) Figure 1 shows the percentage of hits in Stroop test evidencing the almost 100\% assertiveness in neutral stimuli pre and post experimental sessions while shows more heterogeneous answers in incongruent stimuli. The reduction in answer time in the neutral stimuli was greater for $\mathrm{LL}$ compared to $\mathrm{CON}$ and $\mathrm{HL}$, but it was not different from LL-BFR. (Table 3)

Reduction in answer time of the Stroop test was associated to reduced parasympathetic modulation (RMSSD and $\mathrm{HFms}^{2}$ ) and TPR, and increased HR and CO. (Table 4)

Table 1. Sample features.

\begin{tabular}{|c|c|}
\hline $\mathrm{N}$ & $\left.21(9)^{1} / 12+\right)$ \\
\hline Age (years) & $64.3 \pm 5.04$ \\
\hline \multicolumn{2}{|c|}{ Educational level } \\
\hline Basic level (8y) & 5 \\
\hline High school (11y) & 4 \\
\hline Graduation (15y) & 12 \\
\hline \multicolumn{2}{|c|}{ Anthropometry } \\
\hline Body mass (Kg) & $67.19 \pm 12.53$ \\
\hline Height $(\mathrm{m})$ & $1.63 \pm 0.08$ \\
\hline BMI (kg.m-2) & $25.31 \pm 3.05$ \\
\hline \multicolumn{2}{|c|}{ Strength } \\
\hline 1RM 45 Leg Press $(\mathrm{kg})$ & $161.67 \pm 63.01$ \\
\hline \multicolumn{2}{|c|}{ Cardiovascular } \\
\hline Heart Rate (bpm) & $67.8 \pm 7.6$ \\
\hline Cardiac Output (L/min) & $5.0 \pm 0.9$ \\
\hline TPR (mmHg.min/l) & $1.16 \pm 0.3$ \\
\hline \multicolumn{2}{|c|}{ Cardiac autonomic modulation } \\
\hline $\operatorname{RRi}\left(m s^{2}\right)$ & $887 \pm 99.0$ \\
\hline $\operatorname{SDNN}\left(\mathrm{ms}^{2}\right)$ & $29.0 \pm 11.8$ \\
\hline $\operatorname{RMSSD}\left(\mathrm{ms}^{2}\right)$ & $22.1 \pm 13.4$ \\
\hline LF (n.u.) & $53.8 \pm 21.9$ \\
\hline $\mathrm{HF}\left(\mathrm{ms}^{2}\right)$ & $227.8 \pm 275.8$ \\
\hline $\mathrm{LF} / \mathrm{HF}$ & $2.0 \pm 2.1$ \\
\hline
\end{tabular}

Data are presented in mean \pm standard deviation. BMI: body mass index; 1RM: one repetition maximum; TPR: total peripheral resistance; RRi: RR interval; SDNN: standard deviation of all RR normal intervals; RMSSD: root mean square standard deviation; LF: low frequency; HF: high frequency; LF/HF: sympathovagal balance.
Table 2. Exercise protocol features.

\begin{tabular}{c|c|c|c|c}
\hline & HL & LL & LL-BFR & $\begin{array}{c}\text { p value } \\
\text { (Friedman } \\
\text { test) }\end{array}$ \\
\hline $\begin{array}{c}\text { Exercise } \\
\text { duration (s) }\end{array}$ & $\begin{array}{c}428.4 \\
(406.5 ; 439.5)\end{array}$ & $\begin{array}{c}511 \\
(469.5 ; 565.8)^{* \varnothing}\end{array}$ & $\begin{array}{c}436.8 \\
(429.3 ; 448.2)\end{array}$ & $<0.001$ \\
\hline RPE & $19.0(17.0 ; 20.0)$ & $19.3(19.0 ; 20.0)$ & $19.0(17.5 ; 20.0)$ & 0.454 \\
\hline $\begin{array}{c}\text { Number of } \\
\text { repetitions (mean) }\end{array}$ & $\begin{array}{c}9.6 \\
(8.6 ; 11.4)\end{array}$ & $\begin{array}{c}23.4 \\
(19.9 ; 29.4)^{*} \varnothing\end{array}$ & $\begin{array}{c}17.0 \\
(17.0 ; 17.0)^{*}\end{array}$ & $<0.001$ \\
\hline Exercise Load (Kg) & $\begin{array}{c}132.0 \\
(82.0 ; 174.0)^{\# \varpi}\end{array}$ & $49.5(31.5 ; 62.2)$ & $49.5(31.5 ; 65.2)$ & $<0.001$ \\
\hline
\end{tabular}

Data are presented in median (25th; 75th); RPE: rate of perceived exertion; HL: high load; LL: low load; LLBFR: low load with blood flow restriction; SBP: systolic blood pressure. * Different of $H L$; \# different of $L L ; \varnothing$ different of LL-BFR ( $p<0.008$ for Wilcoxon test).

Table 3. Comparison between deltas (post minus pre) of the experimental protocols for the Stroop Test and effect size of changes.

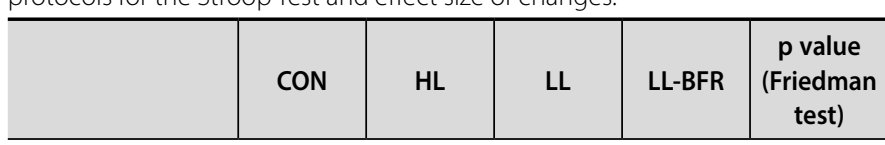

$\Delta$ Number of Hits

\begin{tabular}{c|c|c|c|c|c}
\hline Neutral stimuli & $0(0 ; 0)$ & $0(0 ; 0)$ & $0(0 ; 0)$ & $0(-5 ; 0)$ & 0.579 \\
\hline ES & -0.39 & 0 & -0.06 & -0.58 & \\
\hline Incongruent stimuli & $0(-1 ; 5)$ & $0(-1 ; 1)$ & $0(-5 ; 2)$ & $0(-1.5 ; 1)$ & 0.574 \\
\hline ES & 0.05 & 0.1 & 0.05 & -0.05 & \\
\hline
\end{tabular}

\section{$\Delta$ answer time (ms)}

\begin{tabular}{c|c|c|c|c|c}
\hline Neutral stimuli & $\begin{array}{c}-39.0 \\
(-198 ; 78)^{*}\end{array}$ & $\begin{array}{c}-39.3 \\
(-206 ; 182)^{\#}\end{array}$ & $\begin{array}{c}-255.6(376 ; \\
-65)\end{array}$ & $\begin{array}{c}-130.5 \\
(-237 ; 16)\end{array}$ & 0.006 \\
\hline ES & -0.18 & -0.03 & -0.92 & -0.24 & \\
\hline Incongruent stimuli & $\begin{array}{c}-7.5 \\
(-173 ; 201)\end{array}$ & $\begin{array}{c}-145.9 \\
(-418 ; 21)\end{array}$ & $\begin{array}{c}-130.5 \\
(-448 ; 12)\end{array}$ & $\begin{array}{c}-143.6 \\
(-406 ; 21)\end{array}$ & 0.069 \\
\hline ES & -0.18 & -0.33 & -0.52 & -0.44 & \\
\hline
\end{tabular}

Data are presented in median (25th; 75th). CON: control session; HL: high load; LL: low load; LL-BFR: low load with blood flow restriction; ES: effect size; \# Different of $L L$ ( $p<0.008$ for Wilcoxon test).

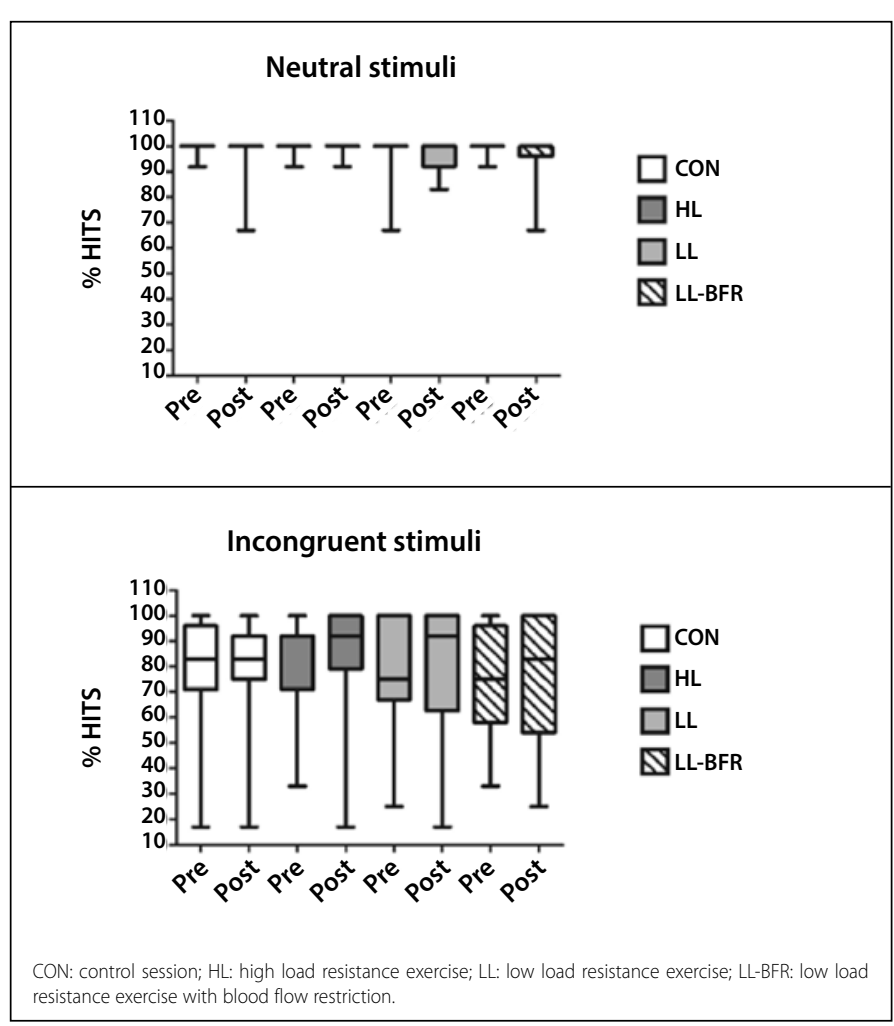

Figure 1. Percentage of hits in Stroop steps, before and after each experimental protocol. 
Table 4. Spearman correlation between cardiovascular variables delta (post minus pre) and answer time Stroop test delta (post minus pre) among all experimental sessions.

\begin{tabular}{c|c|c}
\hline & $\Delta$ Neutral stimuli & $\Delta$ Incongruent stimuli \\
\hline$\Delta$ RRi $\left(\mathrm{ms}^{2}\right)$ & 0.131 & 0.213 \\
\hline$\Delta$ SDNN $\left(\mathrm{ms}^{2}\right)$ & 0.194 & 0.038 \\
\hline$\Delta$ RMSSD $\left(\mathrm{ms}^{2}\right)$ & 0.031 & $0.274^{*}$ \\
\hline$\Delta L F(\mathrm{nu})$ & 0.134 & 0.14 \\
\hline$\Delta \mathrm{HF}\left(\mathrm{ms}^{2}\right)$ & 0.03 & $0.215^{*}$ \\
\hline$\Delta \mathrm{LF} / \mathrm{HF}$ & 0.154 & 0.216 \\
\hline$\Delta \mathrm{HR}(\mathrm{bpm})$ & $-0.283^{*}$ & $-0.254^{*}$ \\
\hline$\Delta \mathrm{CO}(\mathrm{L} / \mathrm{min})$ & $-0.255^{*}$ & -0.16 \\
\hline$\triangle \mathrm{TPR}(\mathrm{mmHg} \cdot \mathrm{min} / \mathrm{l})$ & $0.292^{*}$ & $0.224^{*}$
\end{tabular}

Data are presented in R values. RR: interval; SDNN: standard deviation; RMSSD: root mean square standard deviation; LF (nu): low frequency in normalized units; $\mathrm{HF}\left(\mathrm{ms}^{2}\right)$ : high frequency in absolute values; LF/HF: sympathovagal balance; HR: Heart rate; CO: Cardiac Output; TPR: Total peripheral resistance; * $p<0.05$.

\section{DISCUSSION}

The main finding of the study was the evidence that $L L$ was the most effective RE protocol to improve answer time in Stroop test in older adults compared to the others protocols.

There are incipient evidence regarding the RE effectiveness on cognitive functions. ${ }^{7,21-23}$ Alves et al. ${ }^{7}$ have observed that RE were effective to improve answer time in Stroop, and this effect might be related to processing speed and inhibitory control, both associated with selective attention. In the present study, we observed a large effect size for reduced answer time in neutral and incongruent stimuli after $\mathrm{LL}(\mathrm{ES}>0.5)$, significantly different from CON. The RE protocols showed at least medium effect size of reduction in incongruent stimuli answer time. Contrariwise, the influence over number of hits was null, probably due to the ceiling effect in this high educational level individuals (limited range for improvement).

Since RE improved answer time, we are going to discuss the physiological mechanisms hypothesized to be related to its RE benefits on CF. ${ }^{9}$ We evaluated the cardiac autonomic modulation influence on cognitive function using heart rate variability (HRV). We found interesting positive associations between parasympathetic indexes of HRV (RMSSD and $\mathrm{HFms}^{2}$ ) and Stroop answer time, indicating higher parasympathetic withdrawal, higher the reduction in answer time. Murray et al. ${ }^{10}$ also showed an optimum point (curvilinear association) where exercise-induced sympathetic modulation benefited the trail-making test performance. We did not find associations between Stroop results and sympathetic indexes, only parasympathetic indexes, however we did observe that our RE protocols led to smaller increments in sympathetic modulation, being our higher values around the optimum values found by Murray et al.. ${ }^{10}$

Differences among RE protocols might also be explained by brain blood flow changes. During exercise venous return to the heart increase cardiac output, which in turns increases cerebral blood flow. ${ }^{24,25}$ Moderate intensity endurance exercises $\left(60 \% \mathrm{VO}_{2}\right.$ max) have been pointed as the ideal stimulus for cerebral blood flow increase, being reduced with higher intensities. ${ }^{11}$ We hypothesized that LL might enhance CF due to its higher dynamic cardiovascular predominance compared to the other RE protocols. The others have higher static cardiovascular predominance which might jeopardize cerebral blood flow. Indeed, LL was the most effective and we found significant associations between performance in Stroop and cardiac output as well as with HR, which might influence cerebral blood flow. CF variations could also be associated with the exercise protocols intensity since cerebral oxygenation declines in high intensity exercises, as a consequence of low cerebral perfusion and increase in oxygen cerebral metabolic rate. ${ }^{26}$

Psychological and emotional changes after exercise could also influence CF. ${ }^{9}$ According to Noakes, fatigue is a brain derived emotion, regulating the behaviour during exercise to prevent critical body homeostatic disturbances. ${ }^{27}$ Many body afferents contributes to the definition of the exhaustion. ${ }^{28}$ Although the RE protocols could stimulate the body afferents in different fashions, all RE protocols reached maximal RPE scores without differences among them. Nevertheless, we found that participants expectation for $H L$ were usually worse than $L L$ and LL-BFR, through informal relate of fear. On the other hand, the longest duration of $L L$ yielded more uncomfortable sensations as compared to the discomfort felt at the LL-BFR. Unfortunately, we did not perform specific evaluation to quantify these observations, limiting the comprehension of psychological state influence on CF.

Although muscular and cardiovascular benefits of LL-BFR are already established, 29,30 to our knowledge, its effects on CF were not yet evaluated. Interestingly, we observed a tendency to $L L-B F R$ as well as $L L$ to reduces answer time in Incongruent step different of CON (Wilcoxon test $p=0.020$ and $p=0.028$, respectively). Thus, it is possible that the inability to increase CO sufficiently during LL-BFR (due to its limited venous return) must have been compensated by higher HR increments. The LL-BFR median reduction magnitude in answer time was almost the same than $L L$ (protocol with higher volume), despite larger between subjects variance within LL-BFR. This indicates a potential beneficial effect of LL-BFR on CF which should be explored in future studies. Prodel et al. ${ }^{31}$ investigated the BFR effect performed by young individuals in a cycle ergometer. They showed cerebral blood flow increase induced by muscle metaboreflex activation which also could favor CF in the LL-BFR of the present study. Nevertheless, this type of exercise might have different implications on hemodynamic changes compared to the present study, since the first one has large dynamic component than LL-BFR.

The ceiling effect observed on number of hits limited the evaluation of a RE response on CF since this sample, with high educational level had little room for improvement in this variable. Another limitation was the absence of evaluations for the physiological mechanisms that might explain our results, such as the cerebral blood flow, cerebral activation, neurotransmitters and psychological or emotion evaluation, which might be investigated in future researches.

\section{CONCLUSION}

In summary, we observed that LL had higher effects on CF (reduction in Stroop answer time) than the other protocols. However, similar answer time reductions were found for LL-BFR, implying a potential beneficial effect of blood flow restriction RE on older adults CF which should be investigated in future studies. The higher parasympathetic withdrawal and cardiac output were strong candidates to explain the increase in CF among all RE protocols. These physiological mechanisms are the same pointed to explain aerobic exercise effects. Thus, it seems the higher dynamic cardiovascular predominance of $L L$ and LL-BFR in detriment of higher static predominance of $\mathrm{HL}$ are important determinants of CF improvements through RE in older adults.

All authors declare no potential conflict of interest related to this article.

AUTHORS' CONTRIBUTIONS: Each author made significant individual contributions to this manuscript. AVS (0000-0003-0575-7996)* creation of experimental design, article writing, data collection and analysis; MLVF (0000-0002-9869-6848)* and LCS (0000-0002-6969-4640)*: data collection and review of the article; MSR (0000-0002-2808-9540)* data collection and creation of experimental design; AD (0000-0002-7919-3989)*: writing and review of the article; CRC (0000-0002-7795-6575)*: review of the article; MPTCM (0000-0002-6109-5141)*: review of the article. All authors contributed to the intellectual concept of the study. ${ }^{*}$ ORCID (Open Researcher and Contributor ID). 


\section{REFERENCES}

1. Doherty TJ. Invited review: Aging and sarcopenia. Journal of applied physiology. 2003;95(4):1717-27.

2. Chodzko-Zajko WJ, Proctor DN, Fiatarone Singh MA, Minson CT, Nigg CR, Salem GJ, et al. American College of Sports Medicine position stand. Exercise and physical activity for older adults. Med Sci Sports Exerc. 2009;41(7):1510-30

3. Craik FIM, Salthouse TA. The handbook of aging and cognition. 2nd ed. Mahwah: Lawrence Erlbaum Associates Publishers; 2000.

4. Gomez-Pinilla F, Hillman C. The influence of exercise on cognitive abilities. Compr Physiol. 2013;3(1):403-28.

5. Middleton LE, Barnes DE, Lui LY, Yaffe K. Physical activity over the life course and its association with cognitive performance and impairment in old age. J Am Geriatr Soc. 2010;58(7):1322-6.

6. Pontifex MB, Hillman CH, Fernhall B, Thompson KM, Valentini TA. The effect of acute aerobic and resistance exercise on working memory. Med Sci Sports Exerc. 2009;41(4):927-34.

7. Alves CR, Gualano B, Takao PP, Avakian P, Fernandes RM, Morine D, et al. Effects of acute physical exercise on executive functions: a comparison between aerobic and strength exercise. J Sport Exerc Psychol. 2012;34(4):539-49.

8. Vechin FC, Libardi CA, Conceição MS, Damas FR, Lixandrão ME, Berton RP, et al. Comparisons between low-intensity resistance training with blood flow restriction and high-intensity resistance training on quadriceps muscle mass and strength in elderly. J Strength Cond Res. 2015;29(4):1071-6.

9. Kashihara K, Maruyama T, Murota M, Nakahara Y. Positive effects of acute and moderate physical exercise on cognitive function. J Physiol Anthropol. 2009;28(4):155-64.

10. Murray NP, Russoniello C. Acute physical activity on cognitive function: a heart rate variability examination. Appl Psychophysiol Biofeedback. 2012;37(4):219-27.

11. Ogoh S, Ainslie PN. Cerebral blood flow during exercise: mechanisms of regulation. J Appl Physiol (1985). 2009;107(5):1370-80

12. American College of Sports Medicine. American College of Sports Medicine position stand. Progression models in resistance training for healthy adults. Med Sci Sports Exerc. 2009;41(3):687-708.

13. Mitchell CJ, Churchward-Venne TA, West DW, Burd NA, Breen L, Baker SK, et al. Resistance exercise load does not determine training-mediated hypertrophic gains in young men. J Appl Physiol (1985). 2012;113(1):71-7

14. Brown LE, Weir JP. Procedures recommendation I: Accurate assessment of muscular strength and power. J Exerc Physiol Online. 2001;4:1-21.

15. Stroop JR. Studies of interference in serial verbal reaction. J Exper Psychol. 1935;18(6):643-62.

16. Hernando D, Garatachea N, Almeida R, Casajus JA, Bailon R. Validation of heart rate monitor Polar RS800 for heart rate variability analysis during exercise. Journal of strength and conditioning research / National Strength \& Conditioning Association. 2016.
17. TFotESo. Heart rate variability. Standards of measurement, physiological interpretation, and clinical use. Task Force of the European Society of Cardiology and the North American Society of Pacing and Electrophysiology. Eur Heart J. 1996;17(3):354-81.

18. Romero-Ortuno R, Cogan L, Foran T, Fan CW, Kenny RA. Using the Finometer to examine sex differences in hemodynamic responses to orthostasis in older people. Blood Press Monit. 2010;15(1):8-17.

19. Guelen I, Westerhof BE, van der Sar GL, van Montfrans GA, Kiemeneij F, Wesseling KH, et al. Validation of brachial artery pressure reconstruction from finger arterial pressure. J Hypertens. 2008;26(7):1321-7.

20. Gualano B, Neves M Jr, Lima FR, Pinto AL, Laurentino G, Borges C, et al. Resistance training with vascular occlusion in inclusion body myositis: a case study. Med Sci Sports Exerc. 2010;42(2):250-4.

21. Barella LA, Etnier JL, Chang YK. The immediate and delayed effects of an acute bout of exercise on cognitive performance of healthy older adults. J Aging Phy Act. 2010;18(1):87-98.

22. Harveson AT, Hannon JC, Brusseau TA, Podlog L, Papadopoulos C, Durrant LH, et al. Acute Effects of 30 Minutes Resistance and Aerobic Exercise on Cognition in a High School Sample. Res Q Exerc Sport. 2016;87(2):214-20.

23. Vasques PE, Moraes $H$, Silveira $H$, Deslandes AC, Laks J. Acute exercise improves cognition in the depressed elderly: the effect of dual-tasks. Clinics (São Paulo). 2011;66(9):1553-7.

24. Ogoh S, Brothers RM, Barnes Q, Eubank WL, Hawkins MN, Purkayastha S, et al. The effect of changes in cardiac output on middle cerebral artery mean blood velocity at rest and during exercise. J Physiol. 2005;569(Pt 2):697-704.

25.Kim YS, Seifert T, Brassard P, Rasmussen P, Vaag A, Nielsen HB, et al. Impaired cerebral blood flow and oxygenation during exercise in type 2 diabetic patients. Physiol Rep. 2015;3(6).pii:e12430.

26. Secher NH, Seifert T, Van Lieshout J. Cerebral blood flow and metabolism during exercise: implications for fatigue. J Appl Physiol (1985). 2008;104(1):306-14.

27. Noakes TD. Fatigue is a Brain-Derived Emotion that Regulates the Exercise Behavior to Ensure the Protection of Whole Body Homeostasis. Front Physiol. 2012;3:82.

28. Noakes TD. Time to move beyond a brainless exercise physiology: the evidence for complex regulation of human exercise performance. Appl Physiol Nutr Metab. 2011;36(1):23-35.

29. Slysz J, Stultz J, Burr JF. The efficacy of blood flow restricted exercise: a systematic review \& meta-analysis. Journal of science and medicine in sport / Sports Medicine Australia. 2016;19(8):669-75.

30. Slysz J, Stultz J, Burr JF. The efficacy of blood flow restricted exercise: A systematic review \& meta-analysis. J Sci Med Sport. 2016;19(8):669-75.

31. Prodel E, Balanos GM, Braz ID, Nobrega AC, Vianna LC, Fisher JP. Muscle metaboreflex and cerebral blood flow regulation in humans: implications for exercise with blood flow restriction. Am J Physiol Heart Circ Physiol. 2016;310(9):H1201-9. 